\title{
Comparison of Interval and Aerial Count Methods for Estimating Fisher Boating Effort
}

\author{
ROGER N. LOCKWOOD* \\ Institute for Fisheries Research, \\ University of Michigan and Michigan Department of Natural Resources, \\ 212 Museums Annex Building, Ann Arbor, Michigan 48109, USA \\ GERALD P. RAKOCZY \\ Michigan Department of Natural Resources, Charlevoix Fisheries Research Station, \\ 96 Grant Street, Charlevoix, Michigan 49720, USA
}

\begin{abstract}
Interval and aerial angler creel survey counting methods were compared for a statistical district of Lake Michigan (MM-6) to evaluate potential underestimation of the interval method. Two 0.5-h boat (i.e., interval) counts were made per sample day at five access ports within MM-6, and on the same day, boats in 3 out of 18 MM-6 grids were counted from aircraft. Seasonal and monthly day-type (weekday or weekend day) estimates of boating effort by count method were compared. Seasonal boating effort estimates during open-water periods were not significantly different for aerial versus interval counts: 250,387 versus 247,117 in 2000 and 177,532 versus 219,097 in 2001. Similarly, comparisons of boating effort by monthly day type (i.e., weekday or weekend day) within each year did not indicate significant differences. Aerial precision estimates (2 SEs/estimate; $14.84 \%$ in 2000 and $15.53 \%$ in 2001) were more precise than interval estimates (21.42\% in 2000 and $24.54 \%$ in 2001). Similarly, predicted power (1 - $\beta$ ) was greater for aerial estimates than for interval estimates. The potential power of future interval estimates to detect a $25 \%$ change in boating effort with $\alpha=0.05$ was 0.38 for 2000 data and 0.30 for 2001 data. Aerial estimates provided power estimates of 0.66 for 2000 data and 0.62 for 2001 data. At least four interval counts per sample day are needed to match the precision and power of three aerial counts. Although both count types were made on the same sample days and at approximately the same (random) times each sample day, each method relied on unique estimation methods. Comparable, independent estimates establish the reliability of these two methods.
\end{abstract}

Angler creel surveys are an integral component of fisheries management. Matlock (1991) notes three key tools used to manage sport fisheries. They are regulation of harvest, stocking of fish, and enhancement of habitat. Properly designed and implemented angler surveys are essential to the effective use of each of these tools.

Creel surveys of different types are used in numerous situations where it is necessary to estimate effort and catch. Aerial count design may be used on inland fisheries (Clark et al. 2004; Hanchin et al. 2005), Great Lakes fisheries (Rakoczy and Svoboda 1997; McCullough and Einhouse 2004), and marine fisheries (Fraidenburg and Bargmann 1982). An alternative counting method is the overtime interval or access counting method (Fabrizio et al. 1991; Hayne 1991). Similar to aerial count design, interval counts may be used on inland fisheries (Slipke et al. 1998), Great Lakes fisheries

\footnotetext{
* Corresponding author: lockwoor@michigan.gov
}

Received October 18, 2004; accepted May 25, 2005 Published online October 20, 2005
(Thayer and Wesander-Russell 2003), and marine fisheries (Bernard et al. 1998).

The goals of an angler survey sampling design are to provide accurate and unbiased estimates of angling effort and catch. When these goals are not attained, improper actions may be implemented. Angler surveys may be mandated, for example, in conjunction with data collection by other state, federal, or international agencies to allocate harvest (Thayer and Wesander-Russell 2003). Estimates from these angler surveys are directly linked to this allocation process. The reliability of these estimates is essential to sound decision making and to the credibility of the agency conducting the survey.

Numerous studies have evaluated the accuracy of the instantaneous count method. For example, Pierce and Bindman (1994) made paired comparisons between continuous monitoring of a fishery (census) and instantaneous counts from a stratified random creel survey. Their analysis showed the instantaneous counts had a one-to-one relationship with the census. Similarly, Newman et al. (1997) 
compared estimated effort from random instantaneous counts with a complete census and found no significant difference. Rasmussen et al. (1998) simulated an instantaneous count creel survey using complete creel census data and found no evidence of bias. These evaluations have demonstrated the accurate, unbiased nature of instantaneous count method for estimating angling effort.

The interval count method relies heavily on sampling of all access points to a chosen fishery. When access points are unknown or unsampled, interval count method will underestimate effort (Hayne 1991). In the case of boating effort, a representative sample of individual trips is necessary to accurately estimate boat hours from boats (estimated boats $=$ boat count $\times$ time intervals within daily period $\times$ days within period).

The objective of our study was to compare the accuracy, precision, and power of the interval count method with those of the aerial count method. We hypothesized that the interval count estimates would not differ significantly from the aerial count estimates. However, we were uncertain of their levels of precision and, consequently, statistical power. The goals of angler survey programs are to use survey designs that produce accurate and precise estimates of angling activity at a reasonable cost (Pollock et al. 1994). The purposes of our study were to compare independent sampling methods, and thereby evaluate our hypothesis, and to estimate precision and statistical power for each estimation method.

\section{Methods}

Study area.-For our study site, we selected a statistical district (MM-6) used by the Michigan Department of Natural Resources to evaluate fishing effort in Lake Michigan (Smith et al. 1961). The MM-6 district covers $1,677.2 \mathrm{mi}^{2}$ and is divided into 18 grids varying from $37.0 \mathrm{mi}^{2}$ to 114.2 $\mathrm{mi}^{2}$ (Figure 1). This district has well-defined access sites and little or no alternative access, and its fisheries are located well within the MM-6 boundaries, rather than on or near its boundaries. Access ports in adjacent statistical districts were located considerable distances from its boundaries, so boats from access ports outside of MM- 6 were highly unlikely to fish within our study area. In addition, boats were not readily visible from shore. Because these boat fishers fished some distance from shore, they were highly visible from aircraft and obstructions (e.g., tree canopy) were of no consequence. Thus, MM-6 is an area where both the interval count design and aerial design were appropriate.

Interval count method.-Interval-access angler creel surveys were conducted at the five MM-6 ports (Figure 1). Estimates were made separately for each port and summed for yearly estimates of statistical district boating effort. Variances of port estimates were similarly summed. Survey period was from June 1 to September 30 during 2000 and 2001. Count and interview data were collected by port, and all estimates were made by port. We stratified samples by day type (weekday and weekend day) within each month (Pollock et al. 1994). Count times were randomly selected on every weekend day, and three randomly selected weekdays per week. Holidays were not sampled but were included in the weekend-day strata for each month. Holidays during sample periods were July 4, 2000 and 2001, and Labor Day (September 4, 2000, and September 3, 2001). Interval count and access interview methods are described in Lockwood et al. (1999) and Fabrizio et al. (1991); specific estimation methods are provided here for clarity. In MM-6, survey clerks counted all boats that passed an access site for $0.5 \mathrm{~h}$, twice per day. Sail boats and commercial nonfishing boats (e.g., freighters) were not counted. Although the survey clerks were able to identify fishing boats, the aircraft counters could not distinguish between fishing and nonfishing power boats. Thus, all power boats were also counted by the survey clerks.

It should be noted that for surveys such as these, where counts do not differentiate between fishing and nonfishing power boats, all fishing and nonfishing power boating parties are interviewed and ratios of fishing to total boating parties are used to estimate fishing boat effort from total boating effort (Lockwood et al. 1999). These ratios were not applied to our estimates because the same ratios would have been applied to both interval and aerial estimates and would have only contributed an additional source of variation. Thus, our procedure is more sensitive to differences between methods.

In 2001, one of the five ports (Pentwater) could not be used to estimate effort because of improper collection of interval count data. Aerial estimates were adjusted by removing the grid counts that were adjacent to the missing port (southern tier of grids $7,10,11$, and 12).

Estimated number of boats $B$ on day $d$ from interval count $j$ at port $s$ was estimated as

$$
B_{s d j}=F_{s d} \frac{b_{s d j}}{L_{s d j}},
$$



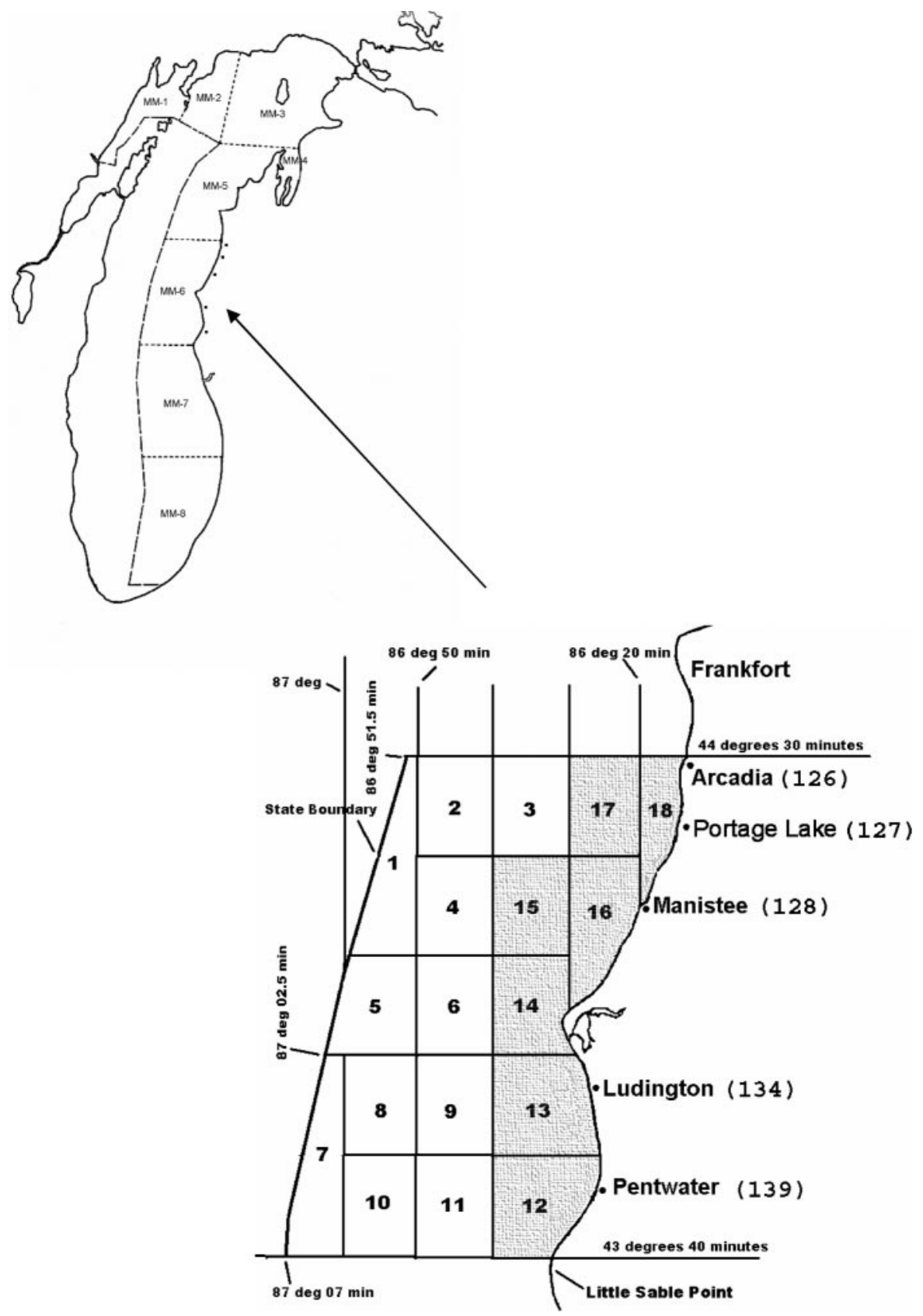

FIGURE 1.-Map of Lake Michigan showing the statistical districts (MM-1 through MM-8) used by the Michigan Department of Natural Resources to evaluate fishing effort in Lake Michigan. The expanded depiction of district MM-6 shows subdivided counting grids for collecting boat effort data. Grids 1-11 are offshore strata; grids 1218 are nearshore strata.

where $F$ is the number of hours within the sample period day $d, b$ the number of boats counted, and $L$ the duration (in hours) of the count. The mean number of boats on day $d, \bar{B}_{s}$ was then

$$
\bar{B}_{s d}=\frac{\sum_{j=1}^{n_{s d}} B_{s d j}}{n_{s d}},
$$


with $n$ counts made on day $d$. The estimated variance of the mean number of boats on day $d$ was

$$
\widehat{\operatorname{Var}}\left(\bar{B}_{s d}\right)=\frac{1}{n_{s d}\left(n_{s d}-1\right)} \sum_{j=1}^{n_{s d}}\left(\bar{B}_{s d}-B_{s d j}\right)^{2} .
$$

From the access interview data set, the mean length of boat-party trip $\bar{e}$ on day $d$ at port $s$ was estimated as

$$
\bar{e}_{s d}=\frac{1}{k_{s d}} \sum_{i=1}^{k_{s d}} \tilde{h}_{s d i}
$$

for $k$ boat angling parties interviewed on day $d$ with $\tilde{h}$ boat hours by party $i$. The estimated variance of the mean length of party trip, $\bar{e}_{\mathrm{sd}}$, was

$$
\widehat{\operatorname{Var}}\left(\bar{e}_{s d}\right)=\frac{1}{k_{s d}\left(k_{s d}-1\right)} \sum_{i=1}^{k_{s d}}\left(\bar{e}_{s d}-\tilde{h}_{s d i}\right)^{2} .
$$

Estimated boat hours on day $d$ were

$$
E_{s d}=\bar{B}_{s d} \bar{e}_{s d},
$$

and the estimated variance (Goodman 1960) was

$$
\begin{aligned}
\widehat{\operatorname{Var}}\left(E_{s d}\right)= & \bar{B}_{s d}^{2} \widehat{\operatorname{Var}}\left(\bar{e}_{s d}\right)+\bar{e}_{s d}^{2} \widehat{\operatorname{Var}}\left(\bar{B}_{s d}\right) \\
& -\widehat{\operatorname{Var}}\left(\bar{e}_{s d}\right) \widehat{\operatorname{Var}}\left(\bar{B}_{s d}\right) .
\end{aligned}
$$

Daily boat effort estimates were summed by day type (weekday or weekend day) within period $p$ (month) for each port:

$$
E_{s p}=\frac{D_{s p} \sum_{d=1}^{m_{s p}} E_{s d}}{m_{s p}},
$$

having a total of $D$ days with $m$ days sampled. The variance of $E_{s p}$ was estimated as

$$
\begin{aligned}
\widehat{\operatorname{Var}}\left(E_{s p}\right)= & \frac{D_{s p}^{2}}{m_{s p}}\left(1-\frac{m_{s p}}{D_{s p}}\right)\left[\frac{\sum_{d=1}^{m_{s p}}\left(\bar{E}_{s p}-E_{s d}\right)^{2}}{\left(m_{s p}-1\right)}\right] \\
& +\frac{D_{s p}}{m_{s p}} \sum_{d=1}^{m_{s p}} \widehat{\operatorname{Var}}\left(E_{s d}\right) .
\end{aligned}
$$

Equation (9) is derived from Cochran (1977:278; equation 10.15); the primary sampling unit is days and the secondary sampling unit is count periods within days. Few secondary units were sampled on any given day (2 of 32-36). Consequently, the finite population correction term was ignored, and secondary sampling unit variances were expanded to estimate total secondary sampling unit variation for the multiple-day period.
Port estimates were summed for the total MM6 boat effort estimate for each sample year. Variances were similarly summed.

Aerial count method.-Aerial counts of boating effort were made on the same days as shore-based angler surveys and approximately coincided with one of the daily interval count times. One flight was made per sample day. We stratified aerial counts by grid distance from land (Figure 1) because we reasoned that near-shore grids would have greater boating effort and greater variance than offshore grids. The stratification made it possible to devote more sampling effort to strata with greater boating effort and variance; therefore, pilots counted two grids near shore and only one grid offshore per sample day. Daily grid count order was randomized.

Individual offshore strata $l$ counts $C$ were expanded by the number of area units $A$, and total sample period day-type hours $F$ within period $p$ to give an estimate of boating effort based on day $j$ :

$$
E_{j}=C_{j} A F_{p} .
$$

Averaging for $m_{p}$ days sampled within multipleday period $p$, we estimated day-type effort as

$$
\hat{E}_{l p}=\frac{\sum_{i=1}^{m_{p}} E_{p i}}{m_{p}} .
$$

The variance of $\hat{E}_{l p}$ was estimated as

$$
\widehat{\operatorname{Var}}\left(\hat{E}_{l p}\right)=\frac{D_{p}-m_{p}}{D_{p}} \frac{\sum_{i=1}^{m_{p}}\left(\hat{E}_{l p}-E_{p i}\right)^{2}}{m_{p}\left(m_{p}-1\right)} .
$$

For the nearshore stratum $h$, estimated boat effort based on day $j$ for period $p$ with total sample period day-type hours $F$ was

$$
\bar{E}_{j}=\frac{\sum_{i=1}^{n} C_{i} A F_{p}}{n} .
$$

The estimated variance of $\bar{E}_{h p}$ was

$$
\widehat{\operatorname{Var}}\left(\bar{E}_{h p}\right)=\frac{\sum_{i=1}^{n}\left(\bar{E}_{h p}-C_{i} A F_{p}\right)^{2}}{n(n-1)} .
$$

Total estimated boating effort with $m$ days sampled for a day type in multiple-day period $p$ was 


$$
\hat{E}_{h p}=\frac{\sum_{i=1}^{m_{p}} \bar{E}_{h i}}{m_{p}},
$$

and the estimated variance of $\hat{E}_{h p}$ was

$$
\begin{aligned}
\widehat{\operatorname{Var}}\left(\hat{E}_{h p}\right)= & \frac{D_{p}^{2}}{m_{p}}\left(1-\frac{m_{p}}{D_{p}}\right)\left[\frac{\sum_{d=1}^{m_{p}}\left(\hat{E}_{h p}-\bar{E}_{h d}\right)^{2}}{\left(m_{p}-1\right)}\right] \\
& +\frac{D_{p}}{m_{p}} \sum_{d=1}^{m_{p}} \widehat{\operatorname{Var}}\left(\bar{E}_{h d}\right) .
\end{aligned}
$$

Similar to equation (9), the finite population correction term for secondary sampling units was ignored because a small fraction of grids and hours were sampled per day.

Nearshore and offshore estimates $\hat{E}_{l}$ and $\hat{E}_{h}$ were summed by day type for the total statistical district estimate of multiple-day period $p$ boating effort. Similarly, $\widehat{\operatorname{Var}}\left(\hat{E}_{l}\right)$ and $\widehat{\operatorname{Var}}\left(\hat{E}_{h}\right)$ were summed to estimate variance of total statistical district estimate of multiple-day period $p$ boating effort. Monthly estimates were summed for annual estimates.

Comparison of interval and aerial estimates.We computed boating effort with both estimation methods. Day-type within month and annual aerial estimates were compared with monthly day-type and annual interval estimates for each year by using multiple $t$-tests with Bonferonni adjustments (Miller 1981; Snedecor and Cochran 1989). In some cases the equal variance assumption, as required for parametric statistical tests, was violated. In these cases, the Welch approximation was used to estimate degrees of freedom (Remington and Schork 1970) by using the number of counts made by each estimation method and the variance of each estimate for a given period (day-type within month or annual). To further evaluate nearshore and offshore stratification, variances of annual estimates were compared with multiple $F$-tests. Note that overall differences between the two creel method estimates was deemed significant at $P<$ 0.05 when a $P$-value from any individual comparison was less than 0.0028 (i.e., $\alpha=0.05 / 18$ ). Comparisons were considered different at $\alpha=$ 0.05 , adjusted by number of comparisons. Unless otherwise noted, estimates are given with 2 SE.

Precision and power.-The precision $(\mathrm{Pr})$ of the annual estimates was made by sample year and estimated as:

$$
\operatorname{Pr}=\frac{2(\mathrm{SD} / \sqrt{N})}{\hat{E}}
$$

TABLE 1.-Total seasonal boating effort estimates in Lake Michigan statistical district MM-6 by interval and aerial counting methods. The Bonferroni technique for multiple comparisons of aerial and interval estimates was

\begin{tabular}{|c|c|c|c|}
\hline Interval & Aerial & $\mathrm{df}$ & $P$ \\
\hline \multicolumn{4}{|c|}{ Year: 2000} \\
\hline $247,117(52,931)$ & $250,387(37,150)$ & 643 & 0.9194 \\
\hline \multicolumn{4}{|c|}{ Year: 2001} \\
\hline $219,097(53,761)$ & $177,532(27,570)$ & 434 & 0.1696 \\
\hline
\end{tabular}
used to adjust $P$-values $(\alpha=0.05 / 18=0.0028)$. Estimated degrees of freedom are given for each comparison. Two standard errors of estimates are given in parentheses.

with $N$ counts made per year. Measures of precision using SE relative to the estimate provide direct measures of variability and are common measures of angler survey precision (Fabrizio et al. 1991; Newman et al. 1997). Interval survey precision was evaluated for $2-16$ counts per sample day (421-3,368 total counts in 2000; 316-2,528 total counts in 2001). Precision of aerial estimates was evaluated for 3-16 counts per sample day (225-1,125 total counts in $2000 ; 140-700$ total counts in 2001).

Potential power $(1-\beta)$ was evaluated for each sample year using PASS (power analysis and sample size) software (Hintze 1996). Interval counts were varied from 2 to 16 counts per day for power to detect a $25 \%$ change in boating effort ( $t$-test, equal variance, $\alpha=0.05)$. Similarly, potential power of aerial estimates was evaluated for 3-16 counts per sample day.

\section{Results}

\section{Aerial and Interval Estimates}

In 2000 the aerial estimate of seasonal effort was not significantly different from the interval estimate $(t=0.05, P=0.92, \mathrm{df}=643$; Table 1$)$. The aerial estimate of boating effort was 250,387 $\mathrm{h}$ and the interval estimate was $247,117 \mathrm{~h}$. Similarly, for the eight day-type within-month comparisons, no significant differences $(\alpha=0.0028)$ were detected $(t=0.05, P=0.29-0.99$, df $=58-$ 95; Figure 2; Table 2).

In 2001, the aerial estimate of seasonal effort was not significantly different from the interval estimate $(t=0.05, P=0.17, \mathrm{df}=434$; Table 1$)$. The aerial estimate of boating effort was 177,532 $\mathrm{h}$, and the interval estimate was $219,097 \mathrm{~h}$. Similarly, for the eight day-type within-month comparisons no significant differences $(\alpha=0.0028)$ were detected $(t=0.05, P=0.01-0.99$, df $=34-$ 70; Figure 3; Table 2). 


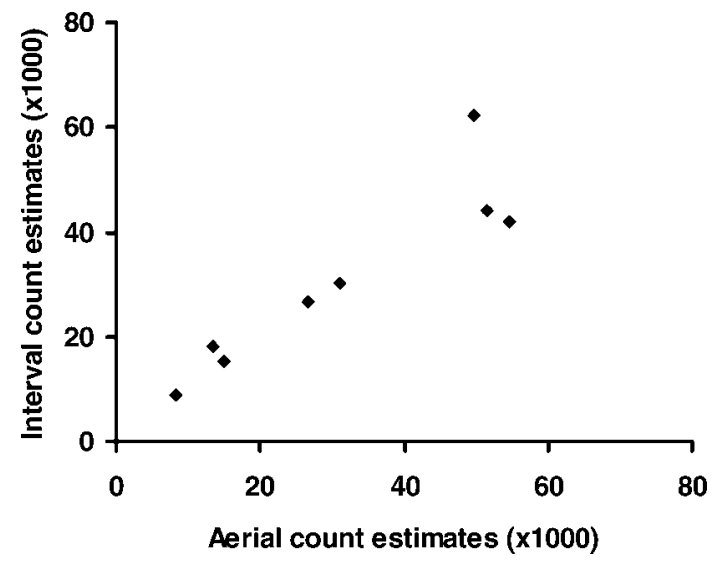

FIGURE 2.-Year 2000 day-type $\times$ month comparisons of interval boat-count estimates and aerial boat-count estimates of boat effort in Lake Michigan statistical district MM-6.

\section{Offshore and Nearshore Estimates}

Estimated variances were significantly different for both sample years. Estimated offshore variance of 2,389,589 in 2000 was smaller than estimated nearshore variance of $342,633,138(F=0.05, P$ $<0.0001$, df $=74,149$ ). During 2001, offshore variance of $1,560,456$ was also smaller than estimated nearshore variance of 188,468,008 $(F=$ $0.05, P<0.0001$, df $=39,99)$.

\section{Precision and Power}

Interval count estimates were most precise in 2000 (Figure 4; Table 3). Two counts per sample day provided precision of $21.42 \%$ in 2000 and $24.54 \%$ in 2001 . Aerial estimates followed a similar trend, 2000 estimates being more precise than 2001 estimates. Aerial estimates had precision of $14.84 \%$ in 2000 and $15.58 \%$ in 2001.

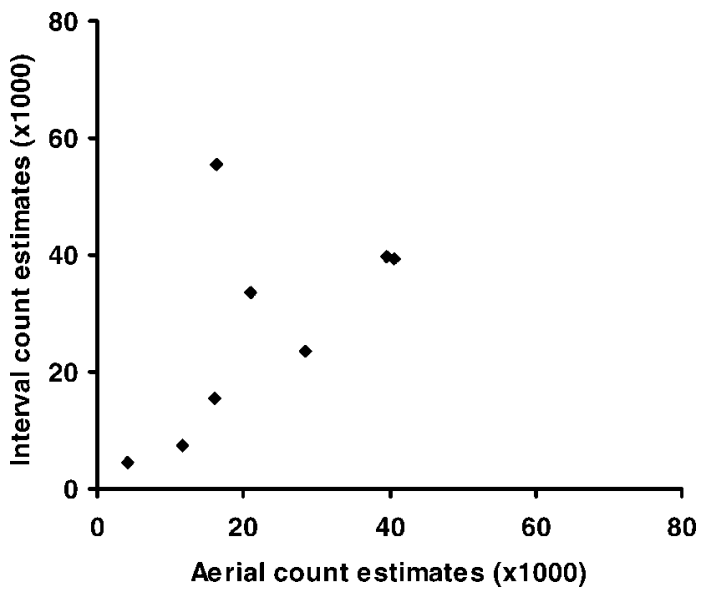

FIGURE 3.-Year 2001 day-type $\times$ month comparisons of interval boat-count estimates and aerial boat-count estimates of boat effort in Lake Michigan statistical district MM-6.

Aerial estimates were more precise than interval estimates each sample year. To attain similar precision (about 15\%) using 2000 interval count data, 842 season counts (4 counts/d) would be necessary; 1,053 season counts ( 5 counts/d) would be necessary based on 2001 data (Table 3).

Both the aerial and interval methods would require increases in counting effort to attain precision of about $10 \%$ (Table 3 ). Interval count data from 2000 would require 1,895 season counts (9 counts/d), and 2001 data would require 1,896 season counts (12 counts/d). Aerial count data from 2000 would require 450 season counts ( 6 counts/d) and 2001 data would require 327 season counts ( 7 counts/d).

Relatively low power is associated with the current numbers of counts for both the aerial and in-

TABLE 2.-Boating effort estimates by interval and aerial counting methods for each period. Bonferroni technique for multiple comparisons was used to adjust $P$-values $(\alpha=0.05 / 18=0.0028)$. Estimated degrees of freedom are given for each comparison. Two standard errors of estimates are given in parentheses.

\begin{tabular}{|c|c|c|c|c|c|c|c|c|}
\hline \multirow[b]{2}{*}{ Period } & \multicolumn{4}{|c|}{ Weekday } & \multicolumn{4}{|c|}{ Weekend day } \\
\hline & Interval & Aerial & df & $P$ & Interval & Aerial & $\mathrm{df}$ & $P$ \\
\hline \multicolumn{9}{|c|}{ Year: 2000} \\
\hline Jun & $8,888(5,254)$ & $8,260(2,504)$ & 95 & 0.8296 & $18,003(7,502)$ & $13,508(5,604)$ & 60 & 0.3410 \\
\hline Jul & $41,843(15,725)$ & $54,594(14,451)$ & 90 & 0.2910 & $30,081(17,819)$ & $31,055(13,374)$ & 69 & 0.9305 \\
\hline Aug & $62,362(32,262)$ & $49,752(17,649)$ & 92 & 0.4942 & $43,926(18,023)$ & $51,470(20,395)$ & 58 & 0.6022 \\
\hline Sep & $15,344(20,507)$ & $14,959(11,846)$ & 73 & 0.9736 & $26,670(19,152)$ & $26,788(9,324)$ & 64 & 0.9911 \\
\hline \multicolumn{9}{|c|}{ Year: 2001} \\
\hline Jun & $7,431(4,774)$ & $11,534(2,176)$ & 62 & 0.1227 & $15,490(7,167)$ & $15,930(4,767)$ & 44 & 0.9378 \\
\hline Jul & $39,306(15,248)$ & $40,625(12,767)$ & 68 & 0.9091 & $33,417(25,233)$ & $21,018(10,898)$ & 43 & 0.3720 \\
\hline Aug & $55,550(27,994)$ & $16,209(12,425)$ & 70 & 0.0123 & $39,766(25,778)$ & $39,626(13,396)$ & 34 & 0.9948 \\
\hline Sep & $4,518(3,215)$ & $4,056(2,958)$ & 53 & 0.8599 & $23,621(22,100)$ & $28,535(10,408)$ & 48 & 0.6892 \\
\hline
\end{tabular}




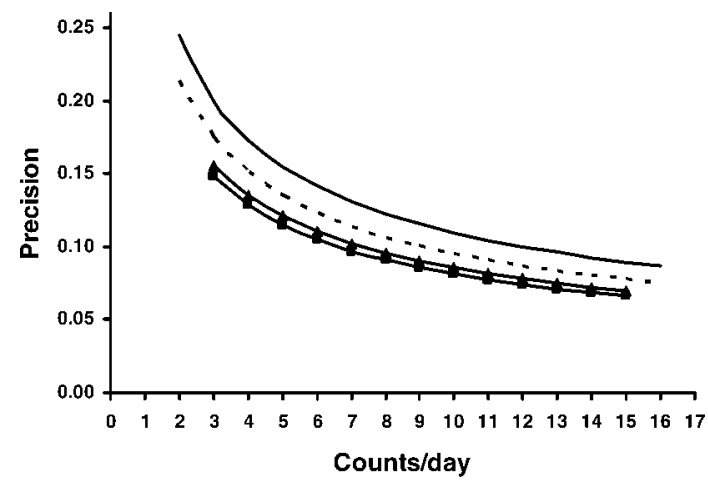

FIGURE 4.-Estimated precision of boating effort based on number of interval counts per day in Lake Michigan statistical district MM-6. Precision was the quotient of 2 SEs of an estimate and the estimate. The dashed line is the 2000 interval boat-count precision, the solid line is the 2001 interval boat-count precision, the solid line with boxes is the 2000 aerial boat-count precision, and the solid line with triangles is the 2001 aerial boat-count precision.

terval methods. Potential power of future interval count surveys (Hoenig and Heisey 2001) to detect a $25 \%$ change in effort with $\alpha=0.05$ provided power of 0.38 based on 2000 data and 421 season counts and a power of 0.30 based on 2001 data and 316 season counts (Figure 5; Table 4). Potential power of future aerial surveys $(\Delta=25 \%, \alpha$ $=0.05)$ was greater than interval surveys for each sample year. Year 2000 provided potential power of 0.66 and 225 season counts and 2001 provided potential power of 0.62 and 140 season counts. To

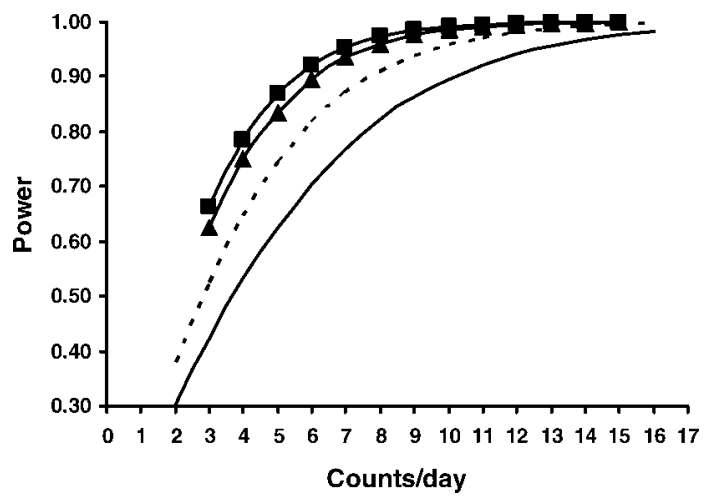

FIGURE 5.-Potential power to detect a $25 \%$ reduction in estimated boating effort based on current data, Lake Michigan statistical district MM-6. Power estimates were based on a $t$-test comparison of two estimates with equal SDs. The dashed line is the 2000 interval boatcount power, the solid line is the 2001 interval boatcount power, the solid line with boxes is the 2000 aerial boat-count power, and the solid line with triangles is the 2001 aerial boat-count power.

attain similar power using interval counts, 2000 data predicted 842 season counts ( 4 counts/d) and 2001 data predict 790 season counts (5 counts/d).

Both the aerial and interval methods required substantial increases in counting effort to attain power of about 0.90 . Interval count data from 2000 required 1,684 season counts ( 8 counts/d), and 2001 data required 1,580 season counts ( 10 counts/ d). The 2000 aerial data required 450 season counts ( 6 counts/d), and 2001 data required 280 season counts $(6$ counts/d).

TABLE 3.-Estimated precision of interval count and aerial count annual estimates of boating effort in Lake Michigan statistical district MM-6 at various levels of sampling effort, based on survey years 2000 and 2001. Precision was estimated as the quotient of 2 standard errors of an estimate and the estimate and reported as a percentage.

\begin{tabular}{|c|c|c|c|c|c|c|c|c|}
\hline \multirow[b]{3}{*}{ Counts/d } & \multicolumn{4}{|c|}{ Interval } & \multicolumn{4}{|c|}{ Aerial } \\
\hline & \multicolumn{2}{|c|}{2000} & \multicolumn{2}{|c|}{2001} & \multicolumn{2}{|c|}{2000} & \multicolumn{2}{|c|}{2001} \\
\hline & $\begin{array}{c}\text { Counts/ } \\
\text { season }\end{array}$ & Precision & $\begin{array}{c}\text { Counts/ } \\
\text { season }\end{array}$ & Precision & $\begin{array}{l}\text { Counts/ } \\
\text { season }\end{array}$ & Precision & $\begin{array}{c}\text { Counts/ } \\
\text { season }\end{array}$ & Precision \\
\hline 2 & 421 & 21.42 & 316 & 24.54 & & & & \\
\hline 3 & 632 & 17.49 & 474 & 20.03 & 225 & 14.84 & 140 & 15.58 \\
\hline 4 & 842 & 15.15 & 632 & 17.35 & 300 & 12.85 & 187 & 13.49 \\
\hline 5 & 1,053 & 13.55 & 790 & 15.52 & 375 & 11.49 & 233 & 12.09 \\
\hline 6 & 1,263 & 12.37 & 948 & 14.17 & 450 & 10.49 & 280 & 11.03 \\
\hline 7 & 1,474 & 11.45 & 1,106 & 13.12 & 525 & 9.71 & 327 & 10.21 \\
\hline 8 & 1,684 & 10.71 & 1,264 & 12.27 & 600 & 9.09 & 373 & 9.56 \\
\hline 9 & 1,895 & 10.10 & 1,422 & 11.57 & 675 & 8.57 & 420 & 9.02 \\
\hline 10 & 2,105 & 9.58 & 1,580 & 10.97 & 750 & 8.13 & 467 & 8.55 \\
\hline 11 & 2,316 & 9.13 & 1,738 & 10.46 & 825 & 7.75 & 513 & 8.16 \\
\hline 12 & 2,526 & 8.74 & 1,896 & 10.02 & 900 & 7.42 & 560 & 7.81 \\
\hline 13 & 2,737 & 8.40 & 2,054 & 9.62 & 975 & 7.13 & 607 & 7.51 \\
\hline 14 & 2,947 & 8.10 & 2,212 & 9.27 & 1,050 & 6.87 & 653 & 7.24 \\
\hline 15 & 3,158 & 7.82 & 2,370 & 8.96 & 1,125 & 6.64 & 700 & 7.00 \\
\hline 16 & 3,368 & 7.57 & 2,528 & 8.68 & 1,200 & 6.42 & 746 & 6.78 \\
\hline
\end{tabular}


TABLE 4.- Potential power of interval count and aerial count estimates of annual boating effort in Lake Michigan statistical district MM-6 at various levels of sampling effort, based on survey years 2000 and 2001. Power is based on detection of a $25 \%$ change in boating effort ( $t$-test, equal variance, $\alpha=0.05$ ).

\begin{tabular}{|c|c|c|c|c|c|c|c|c|}
\hline \multirow[b]{3}{*}{ Counts/d } & \multicolumn{4}{|c|}{ Interval } & \multicolumn{4}{|c|}{ Aerial } \\
\hline & \multicolumn{2}{|c|}{2000} & \multicolumn{2}{|c|}{2001} & \multicolumn{2}{|c|}{2000} & \multicolumn{2}{|c|}{2001} \\
\hline & $\begin{array}{l}\text { Counts/ } \\
\text { season }\end{array}$ & Power & $\begin{array}{l}\text { Counts/ } \\
\text { season }\end{array}$ & Power & $\begin{array}{c}\text { Counts/ } \\
\text { season }\end{array}$ & Power & $\begin{array}{l}\text { Counts/ } \\
\text { season }\end{array}$ & Power \\
\hline 2 & 421 & 0.38 & 316 & 0.30 & & & & \\
\hline 3 & 632 & 0.52 & 474 & 0.42 & 225 & 0.66 & 140 & 0.62 \\
\hline 4 & 842 & 0.65 & 632 & 0.53 & 300 & 0.79 & 187 & 0.75 \\
\hline 5 & 1,053 & 0.75 & 790 & 0.62 & 375 & 0.87 & 233 & 0.84 \\
\hline 6 & 1,263 & 0.82 & 948 & 0.70 & 450 & 0.92 & 280 & 0.90 \\
\hline 7 & 1,474 & 0.87 & 1,106 & 0.77 & 525 & 0.95 & 327 & 0.94 \\
\hline 8 & 1,684 & 0.91 & 1,264 & 0.82 & 600 & 0.97 & 373 & 0.96 \\
\hline 9 & 1,895 & 0.94 & 1,422 & 0.86 & 675 & 0.98 & 420 & 0.98 \\
\hline 10 & 2,105 & 0.96 & 1,580 & 0.90 & 750 & 0.99 & 467 & 0.99 \\
\hline 11 & 2,316 & 0.97 & 1,738 & 0.92 & 825 & 1.00 & 513 & 0.99 \\
\hline 12 & 2,526 & 0.98 & 1,896 & 0.94 & 900 & 1.00 & 560 & 1.00 \\
\hline 13 & 2,737 & 0.99 & 2,054 & 0.96 & 975 & 1.00 & 607 & 1.00 \\
\hline 14 & 2,947 & 0.99 & 2,212 & 0.97 & 1,050 & 1.00 & 653 & 1.00 \\
\hline 15 & 3,158 & 0.99 & 2,370 & 0.98 & 1,125 & 1.00 & 700 & 1.00 \\
\hline 16 & 3,368 & 1.00 & 2,528 & 0.98 & 1,200 & 1.00 & 746 & 1.00 \\
\hline
\end{tabular}

\section{Discussion}

We compared interval and instantaneous count methods to determine accuracy and to estimate the precision and statistical power of each. To determine the accuracy of one or more methods requires a point of reference that has been shown to be unbiased and accurate over a range of conditions. In this study we considered the instantaneous count method as our reference point because previous evaluations had indicated its reliability and unbiased nature.

Our comparisons of interval-count versus aerialcount boating effort estimates support our hypothesis that the interval count method provides accurate estimates of boating effort. Day type within months and seasonal estimates were not significantly different during both years of the study. To ensure comparability of the interval and aerial estimates for this study, counts were scheduled on the same days and at approximately one of the two daily interval counting times. On days when weather prevented flights and no aerial count was made, interval counts for that day were removed from the data set. Cancellations of flights were rare and fewer than five flights were canceled each year. Conversely, ability to make interval counts is not weather-dependent.

Our results are similar to those presented by Jones and Robson (1991), which compared two methods of obtaining angler effort and precision estimates for tributary fisheries along New York's Great Lakes: (1) the traditional access method (re- call that this is a form of the interval count method) and (2) instantaneous car counts taken in a busroute design (Robson and Jones 1989). Jones and Robson (1991) found that both methods provided unbiased estimates of effort, and the estimates from instantaneous car counts were more precise than those from the traditional access method.

Although the aerial and interval counting methods we compared appear to provided reliable estimates of boating effort, each has advantages and disadvantages. Aerial flights are sensitive to weather conditions. For example, aerial counts cannot be made during periods of thunderstorms, fog, or low cloud cover. If boating effort is greater or lesser on days when air flights cannot be made, the aerial method would respectively underestimate or overestimate boating effort. Switching to an aerial design may require an imputation method for estimating boating effort on bad-weather days. For our study estimating boating effort based on the same sample days was appropriate for an unbiased comparison.

Using an aerial design rather than an interval design adds additional expenses because access site clerks are still required. For this study, flights cost US $\$ 12,792$ during the 2000 survey period and $\$ 16,485$ in 2001 . If funding for an angler survey was limited, increased costs of an aerial design could result in inadequate regional coverage or necessitate methods for estimating unsampled areas. This may limit reliability and utility of the angler survey. 
The aerial method allows enumeration of boats within a specified area regardless of their origin. The interval method will underestimate boating effort if boats access the survey area from unsampled sites and over estimate boating effort in an area if boats leave that area.

Similar to those of Jones and Robson (1991), our interval estimates were less precise than aerial estimates each year of the study, and power was greater for aerial estimates than for interval estimates. Four to five interval counts per sample day would be required to attain precision and power of three aerial counts per sample day. Attaining or exceeding the aerial precision and power values is not without cost. In our study, each clerk spent 1 $\mathrm{h}$ per sample day counting boats. The remaining time was spent interviewing anglers. Increasing the number of counts per day decreases the time available for interviewing, thus reducing the number of interviews collected. Jones et al. (1995) reported that approximately 100 access interviews are necessary to attain true $95 \%$ confidence intervals. Similarly, Lockwood (1997) found that 90 access interviews were required to detect a $20 \%$ difference in catch rates (catch/h $\geq 0.10$ ). Because additional counts would be done at the expense of interview time, improving precision and power of effort estimates may result in reduction of precision and power of catch rates. Hiring additional clerks would be necessary to increase precision and power of interval estimates.

Improper collection of interval counts during the 2001 survey season at Pentwater (site 139 located at the southern edge of MM-6) required modification of study area. Overcount of boats at this southern site resulted in exaggerated effort estimates. The inconsistent nature of the overcount prevented correction of boating effort estimates. We believed it was therefore reasonable to remove this southern site from the interval-count and aerial-count data sets for the southern tier of grids. Results of each counting method were compared for an area of similar size.

Nearshore and offshore aerial stratification was appropriate. Estimated variances of boating effort were significantly different between nearshore and offshore areas each year. Without stratification, variability of estimates would have been increased, and reliability and usefulness of comparisons would have been greatly diminished.

This study demonstrates the appropriateness of the interval-access design in our study area. Although statistical evidence for appropriateness of the interval-access design in other areas is not pre- sented here, we suggest that the interval-access design provides accurate estimates of boating effort in areas with similar limited access between sample sites. However, for large geographic areas where boats can access the survey area from unsampled locations, we recommend evaluation of interval-access design using aerial-access design. We recommend at least 2 years of data collection because multiple-year comparisons enable effort estimation evaluations under varying annual conditions, thus broadening the scope of similarities or differences.

\section{Acknowledgments}

Emily Silverman provided assistance with study design and analysis. Zhenming Su provided advice on statistical analysis. Catherine Sullivan supplied flight costs. Mason County Aviation and James E. Norton of Nortec conducted air flights. This paper was reviewed by Lizhu Wang, Sarah Thayer, and edited by James C. Schneider. Additional peer reviews were done by Michael Hansen, Kenneth Pollock, and two anonymous reviewers. Funding for this project was provided by the Michigan Department of Natural Resources through Federal Aid in Sport Fish Restoration, Studies 427 and 646.

\section{References}

Bernard, D. R., A. E. Bingham, and M. Alexandersdottir. 1998. The mechanics of on-site creel surveys in Alaska. Alaska Department of Fish and Game, Special Publication 98-1, Anchorage.

Clark, R. D., Jr., P. A. Hanchin, and R. N. Lockwood. 2004. The fish community and fishery of Houghton Lake, Roscommon County, Michigan, with emphasis on walleye and northern pike. Michigan Department of Natural Resources, Fisheries Division Special Report 30, Lansing.

Cochran, W. G. 1977. Sampling techniques, 3rd edition. Wiley, New York.

Fabrizio, M. C., J. R. Ryckman, and R. N. Lockwood. 1991. Evaluation of sampling methodologies in the Lake Michigan creel survey. Pages 162-176 in D. Guthrie, J. M. Hoenig, M. Holliday, C. M. Jones, M. J. Mills, S. A. Moberly, K. H. Pollock, and D. R. Talhelm, editors. Creel and angler surveys in fisheries management. American Fisheries Society, Symposium 12, Bethesda, Maryland.

Fraidenburg, M. E., and G. C. Bargmann. 1982. Estimating boat-based fishing effort in a marine recreational fishery. North American Journal of Fisheries Management 2:351-358.

Goodman. 1960. On the exact variance of products. Journal of the American Statistical Association 55: 708-713.

Hanchin, P. A., R. D. Clark, Jr., and R. N. Lockwood. 2005. The fish community and fishery of Michi- 
gamme Reservoir, Iron County, Michigan, with emphasis on walleyes and northern pike. Michigan Department of Natural Resources, Fisheries Division, Special Report 33, Lansing.

Hayne, D. W. 1991. The access point creel survey: procedures and comparison with the roving-clerk creel survey. Pages 123-138 in D. Guthrie, J. M. Hoenig, M. Holliday, C. M. Jones, M. J. Mills, S. A. Moberly, K. H. Pollock, and D. R. Talhelm, editors. Creel and angler surveys in fisheries management. American Fisheries Society, Symposium 12, Bethesda, Maryland.

Hintze, J. L. 1996. PASS user's guide. NCSS, Kaysville, Utah.

Hoenig, J. M., and D. M. Heisey. 2001. The abuse of power: the pervasive fallacy of power calculations for data analysis. American Statistician 55:19-24.

Jones, C. M., and D. S. Robson. 1991. Improving precision in angler surveys: traditional access design versus bus route design. Pages 177-188 in D. Guthrie, J. M. Hoenig, M. Holliday, C. M. Jones, M. J. Mills, S. A. Moberly, K. H. Pollock, and D. R. Talhelm, editors. Creel and angler surveys in fisheries management. American Fisheries Society, Symposium 12, Bethesda, Maryland.

Jones, C. M., D. S. Robson, H. D. Lakkis, and J. Kressel. 1995. Properties of catch rates used in analysis of angler surveys. Transactions of the American Fisheries Society 124:911-928.

Lockwood, R. N. 1997. Evaluation of catch rate estimators from Michigan access point angler surveys. North American Journal of Fisheries Management 17:611-620.

Lockwood, R. N., D. M. Benjamin, and J. R. Bence. 1999. Estimating angling effort and catch from Michigan roving and access angler survey data. Michigan Department of Natural Resources, Fisheries Research Report 2044, Ann Arbor.

Matlock, G. C. 1991. Use of surveys in decision making. Pages 1-4 in D. Guthrie, J. M. Hoenig, M. Holliday, C. M. Jones, M. J. Mills, S. A. Moberly, K. H. Pollock, and D. R. Talhelm, editors. Creel and angler surveys in fisheries management. American Fisheries Society, Symposium 12, Bethesda, Maryland.

McCullough, R. D., and D. W. Einhouse. 2004. Eastern basin of Lake Ontario creel survey, 2003. New York State Department of Environmental Conservation, Albany.
Miller, R. G. 1981. Simultaneous statistical inferences. Springer-Verlag, New York.

Newman, S. P., P. W. Rasmussen, and L. M. Andrews. 1997. Comparison of a stratified, intensive count creel survey with a mandatory creel census on Escanaba Lake, Wisconsin. North American Journal of Fisheries Management 17:321-330.

Pierce, R. B., and A. G. Bindman. 1994. Comparison of absolute fishing effort and hourly instantaneous angler counts in a small lake. North American Journal of Fisheries Management 14:447-448.

Pollock, K. H., C. M. Jones, and T. L. Brown. 1994. Angler survey methods and their applications in fisheries management. American Fisheries Society, Special Publication 25, Bethesda, Maryland.

Rakoczy, G. P., and R. F. Svoboda. 1997. Sportfishing catch and effort from the Michigan waters of Lakes Michigan, Huron, Erie, and Superior, April 1, 1994March 31, 1995. Michigan Department of Natural Resources, Technical Report 97-4, Ann Arbor.

Rasmussen, P. W., M. D. Staggs, T. D. Beard, and S. P. Newman. 1998. Bias and confidence interval coverage of creel survey estimators evaluated by simulation. Transactions of the American Fisheries Society $127: 469-480$.

Remington, R. D., and M. A. Schork. 1970. Statistics with applications to the biological and health sciences. Prentice-Hall, Englewood Cliffs, New Jersey.

Robson, D. S., and C. M. Jones. 1989. The theoretical basis of an access site angler survey design. Biometrics 45:83-98.

Slipke, J. W., M. J. Maceina, V. H. Travnichek, and K. C. Weathers. 1998. Effects of a 356-mm minimum length limit on the population characteristics and sport fishery of smallmouth bass in the Shoals Reach of the Tennessee River, Alabama. North American Journal of Fisheries Management 18:7684.

Smith, S. H., H. J. Buettner, and R. Hile. 1961. Fishery statistical districts of the Great Lakes. Great Lakes Fishery Commission, Technical Report 2, Ann Arbor, Michigan.

Snedecor, G. W., and W. G. Cochran. 1989. Statistical methods. Iowa State University Press, Ames.

Thayer, S. A., and D. Wesander-Russell. 2003. Measurement of sportfishing harvest in Lakes Michigan, Huron, Erie, and Superior. Michigan Department of Natural Resources, Study Performance Report, Federal Aid in Sportfish Restoration, Project F-81-R4, Ann Arbor. 